\title{
Right hand second lumbrical with accessory belly - A case study with its clinical importance
}

\author{
Brigesh Shahare $^{1}$, Royana Singh ${ }^{2}$, Gajendra Singh ${ }^{2}$ \\ ${ }^{I}$ Department of Anatomy, Gajara Raja Medical College, Gwalior, India. \\ ${ }^{2}$ Department of Anatomy, Institute of Medical Sciences, Banaras Hindu University, Varanasi, India.
}

\begin{abstract}
Lumbricals are very small muscles in the hand but their role is much more important for the fine movements of fingers. So any variation in the lumbrical muscles has great clinical significance. During routine dissection of the right hand of a 55 year old male Indian cadaver, an accessory belly to second lumbrical was observed while in the left hand no variation observed. This accessory belly united with the second lumbrical. This variation might be useful during the routine clinical practices and hand surgeries.
\end{abstract}

Keywords - Lumbrical, accessory belly, origin, flexor digitorum profundus, carpal tunnel syndrome.

\section{Introduction}

The lumbricals are usually four small fasciculi resemble earthworms. The first and second lumbricals are unipennate while third and fourth lumbricals are bipennate muscles. They arise from the tendon of the flexor digitorum profundus (FDP) in the palm. On reaching the dorsal surface of the proximal phalanx, the tendon of each muscle joins the lateral margin of dorsal digital expansion. Second lumbrical arise from the radial side and palmar surface of the tendon of FDP to the middle finger. Second lumbrical is innervated by the median nerve. Lumbricals produce flexion at metacarpo-phalangeal joint and extension at inter-phalangeal joints. As lumbricals contain many muscle spindles and have a long fibre length, they play a role in proprioception [1]. A large number of variations in the lumbrical have been described in the literature, ranging from complete absence to reduction in their numbers or presence of accessory slips [2-4].

In the present case, we observed that an accessory muscle belly of second lumbrical arising from the flexor digitorum profundus tendon going to index finger. The clinical significance of the present case has been discussed.

\section{Case Report}

During routine dissection of the right hand of a 55 year old male Indian cadaver an accessory belly to second lumbricals was observed.

This belly arose from the medial side and proximal surface of the tendon of the flexor digitorum profundus to the index finger in the palm [Fig. 1 \& 2]. The size of accessory belly was same as normal second lumbrical. We also observed that the site of origin of second lumbrical and accessory belly was more proximal than the other lumbricals i.e. $3^{\text {rd }} \& 4^{\text {th }}$ and extended into the carpal tunnel. This accessory belly united with the radial side of the second lumbrical before inserting to the dorsal digital expansion of the index finger. Accessory belly was innervated by a separate twig from the median nerve.

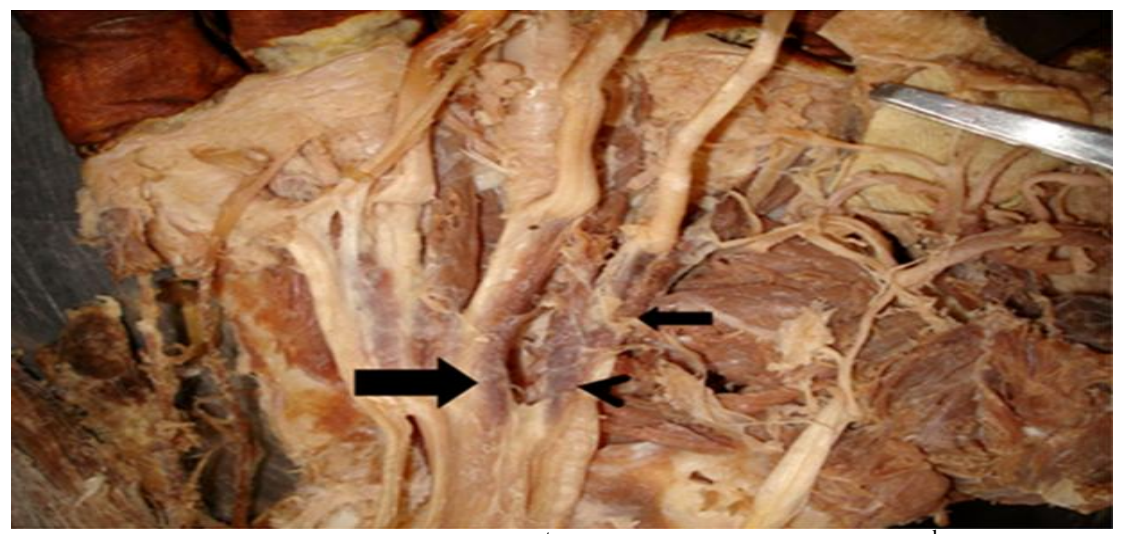

Fig.1 Photograph of the dissected right hand shows $1^{\text {st }}$ lumbrical (thin arrow), $2^{\text {nd }}$ lumbrical (thick arrow), and accessory belly (arrowhead) to $2^{\text {nd }}$ lumbrical after elevation of Flexor digitorum superficialis muscle. 


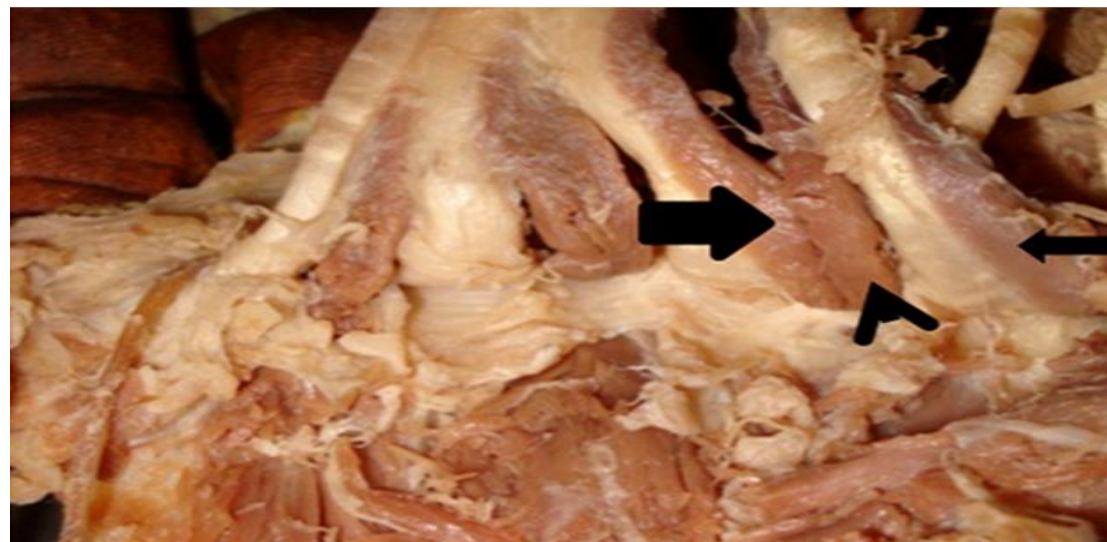

Fig. 2 Photograph of the dissected right hand shows $1^{\text {st }}$ lumbrical (thin arrow), $2^{\text {nd }}$ lumbrical (thick arrow), and accessory belly (arrowhead) to $2^{\text {nd }}$ lumbrical are seen from the posterior side of the tendon of flexor digitorum profundus muscle.

\section{Discussion}

Muscles are subject to variations either in the form of its origin, insertion, absence of muscle or presence of an accessory belly. Usually accessory muscles do not cause symptoms but they become a surgical problem when they produce symptoms or are difficult to differentiate from soft tissue tumors. So these variations are of academic interest.

Because of new imaging techniques, such as computed tomography and magnetic resonance imaging, the anatomical variations and abnormalities of the muscles in the forearm and hand have become easier to detect. During the diagnosis and surgical procedures, an accessory/anomalous muscle may simulate a ganglion or a soft tissue tumor $[5,6]$.

Regarding lumbricals, incidence of accessory belly is more than reduction in number [7]. Various studies show the percentage of bipennate second lumbrical is more than the absence of muscle. In a study conducted by Joshi et al. in 2005, second lumbrical was bipennate in 45\% of cases [8] while Ajmani (2001) showed that it was bipennate in $24 \%$ of cases [4].

Regarding nomenclature of anomalous belly of lumbricals, Ajmani (2001) clarified three new terminologies by comparing with the results of Mehta and Gardner (1961) [2, 4]. These are additional forearm origin, double or supernumerary lumbricals and accessory belly. Additional forearm origins are those fibers originating from the forearm. Theses merge at the varying point with the belly coming from the palmar origin and in no case reach the extensor expansion independently for insertion. Accessory belly is an additional origin from the tendons of flexor pollicis longus, flexor digitorum superficialis, FDP and metacarpals in the palm and eventually attached to the main belly. Double or supernumerary lumbricals are those fibers originate from the forearm or in the palm and reach the insertion in extensor expansion independently. So anomalous belly observed in this case study will be known as accessory belly of second lumbricals.

Entin (1968) grouped causes of carpal tunnel syndrome into three categories: those reducing the capacity of the tunnel; those increasing the volume of its contents; and those forming part of a systemic condition [9]. He also proposed that the origin of the second lumbrical muscle from the tendon in the carpal tunnel can be a cause of carpal tunnel syndrome (CTS). It was observed that during finger flexion, lumbrical muscle incursion into the carpal tunnel takes place [10]. They suggested that incursion is a normal occurrence and is a possible cause of work related CTS. To find out the CTS due to lumbricals muscle incursion in Carpal tunnel, Cobb et al. (1995) described 'fist test' [11]. In this test, person is asked to keep the hand in sustained fist position for 45 seconds it would result in numbness in the area of distribution of median nerve. Our finding in the present case was that the site of origin of second lumbrical and accessory belly was more proximal and extended into the carpal tunnel. They will increase the volume of carpel tunnel contents and may lead to the CTS. So, from this discussion we can conclude that occurrences of such anomalous muscle belly may compress the median nerve and may leads to the CTS.

\section{References}

[1] S. Standring, Gray's Anatomy: The anatomical basis of clinical practices, $40^{\text {th }}$ Ed. Edinburgh: Churchill Livingstone Elsevier, 2008: 886.

[2] H.J. Mehta and W.U. Gardner, A study of lumbrical muscles in the human hand, American Journal of Anatomy, 109, 1961, $227-238$.

[3] R.A. Bergman, S.A. Thompson, A.K. Afifi, and F.A. Saadeh, Compendium of human anatomic variation, Munich, Urban and Schwarzenberg, 17, 1988, 13-14.

[4] M.L. Ajmani, Morphological variations of lumbrical muscles in the human hand with some observations on its nerve supply, Iranian Red Crescent Medical Journal, 3, 2001, 20-25. 
[5] P.R. Lipscomb, Duplication of hypothenar muscles simulating soft-tissue tumor of the hand - Report of a case, Journal of Bone and Joint Surgery (American Volume), 42, 1960, 1058-1061.

[6] A.W. Dunn, Anomalous muscles simulating soft-tissue tumors in the lower extremities - Report of three cases, Journal of Bone and Joint Surgery (American Volume), 47, 1965, 1379-1400.

[7] F. Braithwaite, G.D. Channel, F.T. Moore, and J. Whillis, The applied anatomy of the lumbrical and interosseous muscles of the hand, Guy's Hospital Reports, 97, 1948, 185-195.

[8] S.D. Joshi, S.S. Joshi, and S.A. Athavale, Lumbrical muscles and carpal tunnel, Journal of Anatomical Society of India, 54, 2005, 1215 .

[9] M.A. Entin, Carpal tunnel syndrome and its variants, Surgical Clinics of North America, 48, 1968, 1097-1112.

[10] T.K. Cobb, K.N. An, W.P. Cooney, and R.A. Berger, Lumbrical muscles incursion into the carpal tunnel during finger flexion, Journal of hand Surgery (British Volume), 19, 1994, 434-438.

[11] T.K. Cobb, K.N. An, and W.P. Cooney, Effect of lumbrical muscle incursion within the carpal tunnel on carpal tunnel pressure: a cadaveric study, Journal of hand Surgery (American Volume), 20, 1995, 186-192. 